Rabaska

Revue d'ethnologie de l'Amérique française

\title{
Le patrimoine religieux de la Nouvelle-Écosse. Signes et paradoxes en Acadie
}

\section{Jean-Pierre Pichette}

Volume 4, 2006

URI : https://id.erudit.org/iderudit/201773ar

DOI : https://doi.org/10.7202/201773ar

Aller au sommaire du numéro

Éditeur(s)

Société québécoise d'ethnologie

ISSN

1703-7433 (imprimé)

1916-7350 (numérique)

Découvrir la revue

Citer ce document

Pichette, J.-P. (2006). Le patrimoine religieux de la Nouvelle-Écosse. Signes et paradoxes en Acadie. Rabaska, 4, 138-141. https://doi.org/10.7202/201773ar d'utilisation que vous pouvez consulter en ligne.

https://apropos.erudit.org/fr/usagers/politique-dutilisation/ 


\section{Le patrimoine religieux de la Nouvelle-Écosse. Signes et paradoxes en Acadie}

Jean-Pierre Pichette Chaire Cofram, Université Sainte-Anne

«Quelle improvidence de Dieu !» C'est par cette phrase de Charles Péguy que s'acheva le mot d'ouverture du colloque, entièrement consacré au patrimoine religieux des Acadiens de la Nouvelle-Écosse, qui eut lieu à l'Université Sainte-Anne de Pointe-de-l'Église les 19 et 20 juin 2006 et qui a réuni plus de 80 participants. Cette exclamation, écho d'une inquiétude certaine, en appelait néanmoins à la responsabilité des laïcs devant l'imprévoyance des clercs, d'où la trame qui allait colorer ce rassemblement : " signes et paradoxes en Acadie ». Fruit d'une étroite collaboration avec le Groupe de recherche en études acadiennes (GRÉA), ce premier colloque de la Chaire de recherche sur l'oralité et les traditions populaires des francophonies minoritaires d'Amérique (Cofram) reçut l'appui entier de la Chaire en patrimoine urbain de l'Université du Québec à Montréal (UQAM) et du Forum canadien de recherche publique sur le patrimoine (FCRPP).

Les huit séances et les deux conférences publiques au programme manifestent que les organisateurs, pour mener à bien une telle réflexion, ont voulu associer le milieu universitaire, les organismes de protection du patrimoine et la collectivité acadienne, car ils y avaient convoqué des chercheurs engagés en ce domaine, des spécialistes du Canada possédant une expérience exemplaire, des intervenants du milieu acadien, des chercheurs amateurs, praticiens ou professionnels, que ces questions préoccupent particulièrement. Et, pendant ces deux jours, ils traitèrent, comme des aspects essentiels, autant des signes matériels ou visibles que des signes spirituels, autorisés ou populaires, afin de dresser un premier état des lieux du patrimoine religieux des Acadiens réinstallés en Nouvelle-Écosse, du Cap-Breton à Pompcoup, en passant par la baie Sainte-Marie.

\section{Le volet immatériel}

La première partie de cette rencontre se distribua en quatre séances. Les deux premières s'attachèrent aux empreintes symboliques qui commandent des attitudes spirituelles, mais marquent aussi le domaine matériel. En 
découvrant ces «traces de la foi autorisée », Gérald Boudreau évoqua la grande figure de l'abbé Sigogne, missionnaire de la première moitié du XIX siècle dont il est le biographe confirmé, et évalua l'influence de son apostolat jusqu'à nos jours ; Jean Simard, de l'Université Laval, comparant l'art religieux des Acadiens à celui du Canada français, remit en question la notion de frontières culturelles et s'interrogea sur les liens mystérieux qui uniraient le présent au passé en Nouvelle-Écosse ; et Denise Lamontagne, de l'Université de Moncton, exposa la controverse dont aurait été victime sainte Anne, cette sainte marginale qui a peut-être vaincu sa rivale, Marie de l'Assomption, dans le cour des Acadiens. Cette communication s'enchaînait bien à la séance suivante et débordait sur le terrain plus libre de l'« interprétation des fidèles ». Micheline Laliberté, de l'Université SainteAnne, examina la distance qui aurait existé entre l'enseignement religieux et les pratiques populaires des Acadiens de la baie Sainte-Marie à la fin du $\mathrm{XIX}^{\mathrm{e}}$ siècle quand l'encadrement pastoral pouvait donner prise à certains écarts; et c'est justement un de ces écarts, un très rare cas d'exorcisme populaire documenté, survenu au début du XIX ${ }^{e}$ siècle, qu'analysa Pietro Boglioni, professeur à l'Université de Montréal.

\section{Le volet matériel}

Pénétrant résolument dans la dimension matérielle, les deux séances suivantes portèrent entièrement sur les "lieux de culte" de quatre régions de la Nouvelle-Écosse. Chacun des intervenants présenta quelques-uns des principaux temples acadiens, relevant du patrimoine bâti -église ou chapelle, avec leurs trésors, et cimetière composant l'enclos paroissial - de sa région. Ils en soulignèrent l'évolution, depuis leur érection à nos jours, et les modifications causées par les agrandissements, les incendies, les réformes liturgiques, la pratique religieuse ou la société elle-même en caractérisant aussi le rôle des prêtres qui y furent affectés. Pour le Sud-Ouest, le père Maurice LeBlanc, prêtre eudiste, fit connaître l'église Saint-Pierre de PubnicoOuest, et Jean-Louis Robichaud, directeur du Centre provincial de ressources pédagogiques, celle du Sacré-Cœur de Saulnierville ; pour sa part, Albert Dugas, professeur à l'Université Sainte-Anne, illustra l'œuvre de l'entrepreneur Léo-Jean Melanson, bâtisseur de l'église Sainte-Marie. Pour l'île-du-Cap-Breton, Gabriel LeBlanc, qui a œuvré dans l'enseignement, traita de l'église Notre-Dame de l'Assomption d'Arichat, qui fut un moment promue au rang de cathédrale, et de ses trésors, tandis que Marie-Colombe Robichaud, auteur et éditeur, brossa l'histoire de l'église centenaire de Saint-Pierre de Chéticamp, son village natal, et de celles qui l'ont précédée. Enfin, Sally Ross, spécialiste de l'Acadie, mit en rapport ces quatre régions en suggérant les particularités et la valeur patrimoniale de leurs vieux cimetières. Il ressort 
de ces exposés que l'incurie du clergé, son ignorance des usages, comme de la valeur du patrimoine religieux, et parfois même sa bêtise expliquent en très grande partie la détérioration du mobilier de certaines églises ; il est clair toutefois qu'il reste encore de beaux ensembles qu'il faudra tâcher de protéger. Aussi, ces deux séances manifestèrent-elles la qualité du travail de ces historiens locaux et chercheurs indépendants qui ont étudié ces monuments culturels en dehors des institutions officielles.

\section{Conférences publiques}

Les deux conférences programmées en soirée répondaient au même objectif de sensibiliser le grand public à des aspects moins connus de ce patrimoine. Renforcé par un support audiovisuel de pointe transporté in situ, Luc Noppen, titulaire de la Chaire de recherche en patrimoine urbain à l'UQAM, fit voir l'originalité de la monumentale église Sainte-Marie ; en montrant la place qu'elle occupe dans l'avènement d'un style néo-breton au Canada français, il insista sur le rôle du père Pierre-Marie Dagnaud dans ce retour à une architecture « à la française », que ce dernier lança à Pointe-de-l'Église puis implanta ailleurs en Nouvelle-Écosse, au Nouveau-Brunswick et au Québec. De même, Sally Ross, qui avait conçu sa conférence comme une promenade parmi les cimetières de la baie Sainte-Marie, exposa, par des exemples choisis, la manière dont les historiens et les généalogistes savent faire parler les vieilles pierres tombales oubliées dans nos silencieux cimetières.

\section{L'avenir du patrimoine religieux}

La deuxième partie du colloque, soit les quatre dernières séances, porta entièrement sur l'avenir du patrimoine religieux. Dans la cinquième séance intitulée "Quand l'État s'engage », les représentants des organismes responsables de la protection du patrimoine firent part de leurs politiques et de leurs activités en cette matière, notamment dans le domaine religieux : Gwénaëlle Le Parlouër, de Parcs Canada, présenta la politique fédérale de protection des sites patrimoniaux et le programme d'Initiative des endroits historiques ; Jill Scott, de la Direction du patrimoine de la Nouvelle-Écosse, résuma la loi de Protection du patrimoine bâti, et Delphis Comeau, administrateur de la municipalité de Clare, traita des engagements passés et présents pour la sauvegarde du patrimoine local.

La sixième séance, "Quand l'Église démissionne 》, fut consacrée à un cas concret, actuel et particulièrement exemplaire, celui de la résistance de deux collectivités françaises du sud-ouest ontarien, dont l'évêque du lieu avait ordonné la démolition des églises paroissiales. Les interventions d'André Chénier et de David Tremblay, membres du collectif SOS-Églises, témoignèrent des dangers qui menacent ce type de patrimoine et proposèrent des mesures de prévention adaptables aux particularités du milieu acadien. Car, 
il ne faut pas se leurrer, sous le couvert religieux, opèrent aussi des enjeux politiques, sociaux et culturels. L'expérience ontaroise contribua à approfondir le volet identitaire de ce patrimoine en Acadie où il a joué le rôle de rassembleur en tandem étroit avec la langue française.

Après quoi, à la septième séance, Maurice Lamothe, professeur à l'Université Sainte-Anne, proposa une synthèse des communications, y ajoutant les réflexions que lui avaient inspirées les délibérations et les commentaires des intervenants. Cet exercice favorisa les échanges sur les projets d'avenir et de mise en valeur du patrimoine religieux acadien de la Nouvelle-Écosse au cours de la période de discussion qui forma la séance finale. Est-il en bon état ou en danger ? Qu'adviendra-t-il des édifices, des monuments, des trésors de ce patrimoine religieux dans un monde qui évacue la dimension spirituelle ? Qui en est le garant ? L'Église qui le gère ou le peuple acadien qui le finance ? Faut-il attendre une crise pour agir ? Questions importantes, essentielles, qui déboucheront peut-être sur des projets concrets...

Après coup, il apparaît que ce colloque visait avant tout à éveiller les chercheurs à la situation du patrimoine religieux acadien, puis à sensibiliser la population acadienne de la Nouvelle-Écosse à cette portion significative de sa culture, aux dangers qui la menacent et, enfin, à explorer les voies qui lui garantiront un avenir. Si l'on en juge par les propos échangés au cours de la séance finale, il semble que les délibérations, selon le vœu du comité organisateur, aient produit les fruits attendus et que des actions véritables s'enclencheront pour assurer un avenir à ces biens culturels, qui sont, en définitive, des signes vitaux de la présence française des Acadiens de la Nouvelle-Écosse. 